\title{
Avaliação da qualidade do serviço online prestado pelos aplicativos móveis para delivery utilizando a escala SERVQUAL adaptada
}

\section{Evaluating the quality of the online service provided by mobile applications for delivery, use an adapted SERVQUAL scale.}

\author{
FABIOLA DE MATTOS POTZIK \\ Universidade Anhembi Morumbi \\ LUANA COSTA PIERRE DE MESSIAS \\ Universidade Anhembi Morumbi \\ SÉRGIO LUIS IGNÁCIO DE OLIVEIRA \\ Universidade Anhembi Morumbi \\ PAULO SERGIO GONÇALVES DE OLIVEIRA \\ Universidade Anhembi Morumbi
}

\section{RESUMO}

Este artigo de caráter descritivo, tem como objetivo avaliar a qualidade do serviço online prestado por aplicativos móveis para delivery de refeição, identificando as necessidades de quem utiliza o serviço e apontar os fatores mais críticos. Os métodos empregados para obtenção dos dados foram à pesquisa bibliográfica e documental. A amostra do artigo foi composta por respondentes que conheciam ou não os aplicativos para pedido e delivery de refeição. O levantamento foi realizado através da internet via plataformas sociais como Facebook, Whatsapp e e-mail, por meio de formulário do Google Forms. A aplicação do questionário ocorreu no período de abril a junho de 2017, e obteve-se 110 respostas, das quais todas foram consideradas válidas para fins de pesquisa. Através da análise fatorial os dados obtidos com o questionário foram avaliados, e verificou-se a variância explicada pelo modelo, cuja extração foi efetuada pelo método das "Componentes Principais" e a rotação pelo método "Varimax", gerando uma solução de três constructos, que explica cerca de $70 \%$ da variância total. 
A análise seguinte foi à verificação da confiabilidade interna dos constructos por meio do uso do Alpha de Cronbach para cada um dos três constructos gerados. Os resultados do artigo apontam os fatores determinantes para a aplicação e ampliação de canais de Marketing voltados para delivery de refeições, a segurança no processo de transferência patrimonial e facilidades na interface gráfica dos aplicativos.

Palavras-chave: Aplicativo móvel. Delivery. Marketing de Serviço. Qualidade do serviço.

\section{Abstract}

This descriptive article aims to evaluate the quality of the online service provided by mobile applications for meal delivery, identifying the needs of those who use the service and pointing out the most critical factors. The methods used to obtain the data were bibliographic and documentary research. The sample of the article was composed by respondents who knew or not the applications for ordering and delivery of meal. The survey was conducted through the internet by Facebook, Whatsapp and e-mail, using a Google Forms. The questionnaire was applied in the period from April to June 2017, and 110 responses were obtained, all of which were considered valid for research purposes. Through the factorial analysis the data obtained with the questionnaire were evaluated, and the variance explained by the model was verified, whose extraction was carried out by the "Principal Components" method and the rotation by the "Varimax" method, generating a solution of three constructs, which explains about $70 \%$ of the total variance. The next analysis was to verify the internal reliability of the constructs by using Cronbach's Alpha for each of the three constructs generated. The results of the article indicate the determinant factors for the application and expansion of marketing channels focused on meal delivery, security in the patrimonial transfer process and facilities in the graphical interface of the applications.

Keywords: Mobile apps. Delivery. Service Marketing. Service quality. 


\section{INTRODUÇÃo}

Com as novas tecnologias móveis presentes em mercado nacional, nota-se, há algum tempo, novos padrões de consumo. Pode-se considerar um fator determinante nesses novos relacionamentos a popularização de smartphones no Brasil. Segundo site do Jornal Estado de São Paulo (2017) atualmente existe 198 milhões de celulares inteligentes em uso em território nacional, um crescimento de $17 \%$ em relação à 2016, e com previsão de aumento desses números, já que a previsão para 2017 era a venda de 52,1 milhão de aparelhos, um crescimento de 6\% em relação ao ano anterior (IDC, 2017). Tais mudanças no contexto contribuem para que novas formas de relacionamento entre empresas e consumidores amadureçam no mercado, tornando-se, até certo ponto corriqueiras, como por exemplo, as redes sociais, serviços de streaming, e aplicativos dos mais variados tipos usados tanto para entretenimento, comunicação e consumo.

Mesmo com esse cenário promissor existe em mercado brasileiro, existem indícios de que esse fenômeno ainda é pouco explorado pela academia, ao menos em território nacional, visto que, na literatura estrangeira, esse tema é alvo de estudo há vários anos. Isso implica, portanto, um setor ou área de atuação, carente de análises, principalmente no setor de A\&B (alimentos e bebidas). Todavia, estudos para uma melhor compreensão desse fenômeno apresentam-se como relevante visto que, ao que pode-se notar no mercado, esta alterando o comportamento do consumidor, consumidor esse que, com as plataformas digitais torna-se um agente ativo nesse relacionamento com as organizações. Com o advento dessas novas tecnologias, ele pode através do sistema de rede solicitar e receber um serviço a qualquer momento, impactando o contexto no qual as empresas estão inseriras e forçando-as a adaptar as suas estratégias para uma melhor resposta ao contexto que se apresenta, para que consiga, melhor que os seus concorrentes de mercado, entregar valor de forma sustentável, bem como para criar diferenciais competitivos que permitam enfrentar os seus concorrentes de mercado.

Em especial no setor de alimentos e bebidas esse tipo de serviço surge como uma oportunidade de ampliar o elo entre restaurantes e clientes, tanto na forma de novos relacionamentos com as possibilidades de maior interação entre empresa-marca e consumidor, 
bem como um maior conhecimento por parte das empresas de seu mercado alvo com o uso estratégico do big data. Também, pode-se destacar as estratégias de promoção, como novas plataformas de divulgação de seus produtos e ofertas, e distribuição.

Em relação a distribuição, nota-se com maior frequência no mercado que a maioria dos restaurantes estão formatados para entregar seus produtos e/ou serviços no salão do estabelecimento, contudo devido à violência dos centros urbanos, dificuldades de locomoção e falta de estacionamento, entre outros motivos, muitos clientes buscam atendimento no refúgio do seu lar. Em vista de tal situação, o serviço de delivery tem crescido, em especial o mediado por aplicativos móveis.

Os aplicativos móveis para delivery apresentam uma forma diferenciada de realizar o pedido no qual é possível o usuário controlar o tempo de entrega e a entrada e saída do pedido em todo o seu ciclo de compra e relacionamento. Os usuários desses dispositivos conseguem, literalmente, acompanhar todo o processo de compra, permitindo um maior empoderamento em seu relacionamento com as empresas. O cliente não precisa realizar uma ligação para o restaurante, o que em alguns casos torna-se uma experiência ruim, pois o telefone do restaurante pode estar ocupado, ou o atendente pode anotar o pedido errado, ou o endereço de entrega pode estar incorreto. Esse processo de atendimento feito pelo telefone pode irritar o cliente que precisa repetir constantemente seu pedido e endereço, e ainda pode ter problemas com o seu pedido, recebendo-o em desacordo com o solicitado. Além disso, a forma de pagamento pelos sistemas também é um diferencial, garantindo um maior controle por parte do cliente.

Em se tratando do setor de alimentos e bebidas, objeto de estudo desse artigo, é importante destacar que neste cenário a alimentação fora do lar movimentou $\mathrm{R} \$ 184$ bilhões no Brasil em 2016 (ABRASEL, 2017a). De acordo com a Associação Brasileira da Indústria de Alimentação - ABIA (2017), os negócios relacionados a alimentação fora do lar foi um dos principais beneficiados pela expansão do consumo nos últimos anos, considerando um faturamento de R \$ 38,6 bilhões em 2005, e um valor aproximado de R\$ 140 bilhões em 2014, um crescimento considerável. Apesar do cres- 
cimento do setor de alimentos e bebidas durante o período de 2005 a 2014, frente à atual crise, a partir do ano de 2015 o faturamento real do setor apresentou uma queda de 4,3\% em comparação ao exercício anterior. A ABRASEL (2015) destaca que os restaurantes que mais sofreram foram aqueles com tíquete médio entre $\mathrm{R} \$ 25 \mathrm{e}$ $\mathrm{R} \$ 70$, como uma queda de até $30 \%$ nas vendas.

Destaca-se que o setor de A\&B apresenta em sua configuração um volume expressivo de empreendimentos de pequeno porte (EPP). De acordo com o Sebrae (2016) esses pequenos negócios faturam anualmente de $\mathrm{R} \$ 360$ mil a $\mathrm{R} \$$ 3,6 milhões. A ABIA (2017), destaca ainda que, o setor de $A \& B$ é composto em aproximadamente $85 \%$ por empresas de pequeno e médio porte. Empresas estas que se beneficiam dessas novas configurações de mercado, visto que, com o uso dos aplicativos móveis, elas podem ter acesso a mercados que anteriormente, com uma limitação de espaço físico, ou somente restrito ao seu estabelecimento comercial, não teriam.

Ainda, segundo o instituto Food Service Brasil (2017) o mercado brasileiro é muito fragmentado. Mais de $80 \%$ dos estabelecimentos são independentes; compostos por redes pequenas de até 5 estabelecimentos; 93\% são empreendimentos familiares e de pequeno porte; $64 \%$ deles possuem um faturamento mensal abaixo de $\mathrm{R} \$ 50$ mil.

Já em relação ao segmento de delivery e to go, o faturamento chegou a $\mathrm{R} \$ 9,56$ bilhões em 2016. Somando pedidos feitos por telefone, web e aplicativos a estimativa era de fechar 2017 acima de R\$ 10 bilhões (ABRASEL, 2017b). Nesse mercado destaca-se dois grandes players, Pedido Já e iFood.

A empresa Pedidos Já, uma das maiores no seguimento, começou suas operações na web, e atualmente $80 \%$ dos 3,5 milhões de usuários no Brasil realizamos pedidos pelo aplicativo. Seis mil restaurantes estão cadastrados nessa plataforma.

O líder no mercado de delivery no país é o iFood (EXAME, 2018), empresa global com mais de 70 milhões de clientes em 100 países, no qual entrega 4 milhões de pedidos feitos em sua plataforma ao mês (ISTO É DINHEIRO, 2017). No Brasil possuí 80\% de marketshare, 2 milhões de usuários e mais de 22 mil restaurantes cadastrados em sua plataforma. Tem um tíquete médio de cerca de $\mathrm{R} \$ 80$. Considerando que o aplicativo atende a 2,1 milhões de pedidos por mês 
e cobra uma comissão de $12 \%$, estima-se um faturamento de $\mathrm{R} \$ 20$ milhões por mês.

Em relação aos usuários desse tipo de ferramenta, o iFood realizou uma pesquisa no Brasil, com o objetivo de identificar o perfil e os hábitos de seu usuário. Feita com 1800 pessoas que usam este tipo de serviço, constatou que os pedidos por dispositivos móveis já representam $38 \%$ do total, a maioria das compras são realizadas pela classe B (69\%), sendo (54\%) homens, famílias (41\%), com predomínio da região sudeste do país revelando, também uma grande oportunidade de crescimento, já que, ainda $62 \%$ dos pedidos é realizado por telefone (EXAME, 2017). Ainda em relação a esse comportamento, outra pesquisa realizada pelo ifood em parceria com o IBOPE, publicada pela revista Meio e Mensagem (2016) indica os motivadores de compra: a facilidade de fazer o pedido (64\%), acesso ágil ao cardápio (55\%) e não precisar falar com o atendente (51\%).

Diante destes números essa pesquisa tem como objetivo avaliar a qualidade do serviço online prestado por aplicativos móveis para delivery, identificando as necessidades de quem utiliza o serviço e apontar os fatores mais críticos presentes nessa forma de relacionamento que, como destacado, cresce, tanto em termos de números de adeptos, como de importância para o setor de alimentos e bebidas, apresentando novas formas de pensar estrategicamente a relação entre os agentes presentes no mercado.

O estudo está estruturado em três partes. Além dessa parte introdutória, apresenta-se, à seguir os conceitos que o norteiam e que serviram de base para o desenvolvimento do artigo, depois os materiais e método para a coleta de dados e por último, a discussão dos principais resultados obtidos. Com este apanhado, buscou-se respostas para a seguinte pergunta: Como o usuário de aplicativos móveis para delivery avalia a qualidade do serviço online prestado pelos aplicativos?

\section{FUndAMENTAÇÃo TEÓRICA}

O termo aplicativo para delivery está diretamente relacionado ao conceito de computação móvel (CIRILO, 2007; MATEUS; LOUREIRO, 1998), visto que possuem a capacidade móvel de transportar informações reais ao mesmo tempo que estão conectados à inter- 
net. Desta forma, onde quer que o consumidor esteja, em casa ou no trabalho, ou até mesmo na rua, com o uso de um dispositivo móvel pode, em nosso caso em particular, visto que existem outras formas de relacionamento móvel que não será aprofundado nesse trabalho, realizar pedidos online ao restaurante mais próximo, em tempo real com a possibilidade de pagamento remoto e receber o seu pedido sem demandar muito esforço, ao menos se comparado com o modelo tradicional no qual o cliente tem que se locomover até o restaurante para a realização de todo esse processo.

Com a popularização dessa nova tecnologia em mercado nacional, pode-se afirmar que, conforme destaca, Moraes (2017) é uma mudança na forma de consumir, resultado da influência da inovação incorporada pelos dispositivos móveis, já adaptados pelos profissionais como um canal de Marketing para atender consumidores em qualquer lugar e momento. Pode-se inferir da citação dos autores que os dispositivos móveis, além de proporcionar uma maior agilidade para o consumidor no momento do consumo dos produtos, também permite novas abordagens em termos de Marketing para as empresas.

O uso de aplicativos para compra delivery está relacionado ao M-commerce, visto que, como descreve o estudo de Balasubramanian, Peterson e Jarvenpaa (2002), esse tipo de tecnologia permite um melhor relacionamento entre empresas e consumidores envolve a comunicação, de sentido único ou interativo, entre dois ou mais seres humanos, entre um humano e um ou mais objetos inanimados (como bases de dados), ou entre dois ou mais objetos inanimados (por exemplo, entre dispositivos); pelo menos uma das partes envolvidas no processo comunicacional é móvel, no sentido de que a sua capacidade de comunicação não depende de estar em uma localização física fixa em um determinado momento; a capacidade de comunicação possui potencial de ser mantida continuamente para pelo menos uma das partes durante um movimento físico substancial de um local para outro; se os humanos estão se comunicando, pelo menos um busca se beneficiar economicamente da comunicação; se a comunicação é inteiramente entre objetos inanimados, essa comunicação deve ser, em última instância, destinada a criar benefícios econômicos para um ser humano ou uma empresa. 
Mort e Drennan (2005), ainda completam destacando que M-serviços podem ser definidos como qualquer tipo de serviço que pode ser acessado através de um dispositivo móvel, e que são entregues em um processo de interação entre uma organização e um cliente.

$\mathrm{O}$ processo de relacionamento entre empresas e consumidores tendo como intermediários os dispositivos móveis, pode, em termos de estratégias empresariais, ou seja, a forma pelo qual os gestores podem pensar nas formas de atuação em um determinado mercado, ser administrado pelo viés do Marketing de serviço, uma ramificação das várias estratégias mercadológicas usadas pelas organizações para entregar valor aos seus consumidores em um processo de troca, ou como destaca Vargo e Lusch (2004) em seu processo de co-criação de valor com o objetivo de criar e desenvolver relacionamentos em longo prazo com os seus clientes e agregar valor no processo de troca, sempre em um processo de sinergia entre os envolvidos, visto que, a inter-relação entre as partes torna-se um componente fundamental no processo de desenvolver, criar e entregar valor em uma transação comercial.

É o que se pode entender como uma melhor resposta por parte das empresas as demandas que surgem no mercado, ou uma adaptação por parte das organizações as novas exigências no contexto pelo qual elas estão inseridas (SANEMATSU; SILVA; VIEIRA, 2016), mais especificamente o crescimento dos serviços em economias modernas, visto que, segundo Bhat (2012), o setor de serviços tem se tornado cada vez mais atuante no cenário mundial, e consequentemente, nas economias modernas, desta forma, as organizações necessitam reestruturar suas estratégias de serviços adotando novos posicionamentos em face desse tema.

Também, como destaca Silva e Rocha (2006) à medida que reduz a diferenciação dos produtos, devido as novas tecnologias presentes no mercado, as organizações são forçadas a desenvolver vantagens competitivas centradas na oferta ampliada de serviços, ou seja, a medida que os mercados se desenvolvem, e as tecnologias de produção permitem que os produtos possam ser desenvolvidos e produzidos com qualidade similares aos seus concorrentes de mercado, seja localmente ou em outras nações exportadoras, as organizações necessitam agregar serviços adicionais para que consigam se diferenciar no mercado, e assim entregar uma oferta distinta aos seus clientes alvo. 
Ainda, pode-se afirmar que Marketing de Serviços representa a união de atividades que visam o estudo, o projeto, a execução e o domínio de programas designados a alcançar e servir a exigência por produtos e serviços, de forma ajustada, a satisfazer desejos e dos consumidores. De acordo com Kotler e Keller (2012, p.382) “definimos serviço como qualquer ato ou desempenho, essencialmente intangível, que uma parte pode oferecer a outra e que não resulta na propriedade de nada. A execução de um serviço pode estar ou não ligada a um bem concreto", ou seja, pode-se entender como serviço as ofertas essencialmente intangíveis que uma empresa oferece a um mercado, o seu mercado alvo delimitado em seu planejamento de Marketing, com o objetivo de satisfazer as suas necessidades ou desejos. Cabe ressaltar que para que as empresas possam se manter competitivas, torna-se cada vez mais necessário oferecer serviços adicionais aos seus produtos, assim, o estudo do Marketing de Serviços torne-se algo importante para que os gestores possam pensar em formas de atuar no mercado.

Gronnöos (2017), destaca que os serviços são processos que incluem uma série de ações e interações ofertadas pelo provedor de serviços, e o seu relacionamento com o cliente, nesse processo inclui-se recursos tangíveis e sistemas físicos e digitalizados, bem como pessoas que contribuem nesse processo de interação e criação, ou co-criação de valor.

Em se tratando de entrega de valor, cabe destacar a visão de Vargo e Lush (2008), com a lógica dominante do serviço (S-D), no qual o serviço é definido como a aplicação de competências especializadas (recursos operantes - conhecimento e habilidades), por meio de ações, processos e desempenhos em benefício de outra entidade ou da própria entidade. Reflete o processo de fazer algo benéfico para, e em conjunto, com alguma entidade. O serviço, então, representa o denominador comum, do processo de troca. O serviço é o que sempre é trocado. Os bens, quando empregados, são auxiliares ao processo de fornecimento de serviços.

Ainda segundo os autores utilizados como base para essa pesquisa, existem cinco categorias de serviços ofertados no mercado, a saber: bens puramente tangíveis, bens tangíveis associados a serviços, híbridos, serviço principal associado a bens ou serviços 
secundários e serviço puro. Além disso, os serviços apresentam quatro características principais: intangibilidade, inseparabilidade, variabilidade e perecibilidade (COBRA, 1992; CHURCHIL, 2000; HOFFMAN, 2009; LAS CASAS, 2012; KOTLER; KELLER, 2012; LOVELOCK;WRIGHT, 2003; OLIVEIRA, 2007; PARASURMAN, et al, 2000).

Com base nas definições apresentadas, infere-se então que a atividade desenvolvida pelos aplicativos móveis de delivery pode ser considerado e gerido como um serviço, e por ser essencialmente intangível, ainda pode-se categorizá-los como um serviço puro, visto que sua atividade principal consiste em outra formatação da entrega em domicílio. Porém, cabe destaque que com a servicilização da economia, em muitos casos, essa definição não é mais usual, compreendendo-se que nas economias modernas, tanto produtos como serviços são ofertados em conjunto, não existindo a necessidade de uma distinção entre as duas ofertas.

Os aplicativos ligam através da comunicação móvel o restaurante, o motociclista (transportador) e o consumidor, caracterizando um canal de Marketing, ou seja, age como um intermediário entre as três partes envolvidas. Canais de Marketing "são conjuntos de organizações interdependentes envolvidas no processo de disponibilizar um bem ou serviço para uso ou consumo. Eles formam o conjunto de caminhos que um produto segue depois da produção, culminando na compra ou na utilização pelo usuário final" (KOTLER; KELLER, 2012, p.448)". Ou, as instituições que ajudam as empresas a chegar aos mercados alvo da empresa, os disponibilizando para o consumo (COBRA, 1992; CHURCHIL, 2000; OLIVEIRA, 2007; ROCHA, 2015). Levando-se em consideração tal definição e diante da observação que o restaurante prepara a refeição, o motociclista a transporta até o consumidor que solicitou a refeição pelo aplicativo, então temos no aplicativo além de um serviço, um canal de Marketing.

Instituições que têm por finalidade facilitar as transações entre as empresas e seu mercado-alvo são chamadas de intermediários de Marketing segundo Oliveira (2007). Os intermediários de Marketing possuem as seguintes funções: procura de mercado, distribuição física, comunicação, negociação e transferência de propriedade e padronização (COBRA, 1992; CHURCHIL, 2000; KOTLER; KELLER, 
2012; OLIVEIRA, 2007; ROCHA, 2015).Os aplicativos viabilizam propaganda dos restaurantes em sua plataforma, divulgando seus serviços aos potenciais consumidores, é possível comparar preços entre restaurantes concorrentes, são responsáveis pela distribuição física (buscam a refeição no restaurante, acondicionam no transporte e entregam a refeição na residência do consumidor), negociam a melhor forma de pagamento para o consumidor, por fim, padronizam as ofertas, o material de comunicação e as formas de pagamento, ou seja, contemplam grande parte das funções operacionais de um intermediário de Marketing.

Como afirma Öztaş (2015) o desenvolvimento dos aplicativos móveis permitiu o desenvolvimento de várias formas de relacionamento entre as empresas e os consumidores, como um novo canal de Marketing para fabricantes e varejistas, um meio de compras multimídia, bem como conexão à Internet, manuseio de reservas, compra de bilhetes e comercialização de bens e serviços. Para o autor, uma das abordagens de Marketing mais importantes, que emergiu dessa transformação é o Marketing Direto proporcionado pela Internet. A evolução nas tecnologias da internet proporcionou as empresas o desenvolvimento de formas de atingir o público-alvo sem restrições de hora e local.

Keller e Kotler (2012, p. 397) afirmam que "a qualidade do serviço de uma empresa é testada sempre que o serviço é prestado", por tanto, a qualidade do serviço envolve a comparação entre a expectativa do cliente quanto ao serviço e a percepção do serviço após sua execução. Dito isso, esses autores citam um modelo de qualidade dos serviços desenvolvido por Zeithaml et al (2000), no qual identificam cinco gaps que quando não controlados podem desqualificar a prestação do serviço. Além disso, eles também identificaram cinco fatores determinantes da qualidade dos serviços: confiabilidade, capacidade de resposta, segurança, empatia e itens tangíveis.

A proposta deste artigo baseou-se no estudo A conceptual framework for understanding e-servicequality: implications for future research and managerial practice de Zeithaml, Parasuraman, e Malhotra (2000) nele os autores definem a qualidade do serviço on-line como o grau em que um site torna os processos de pesquisa, compra e entrega eficientes e eficazes. Eles identificaram onze dimensões de quali- 
dade do serviço on-line: acesso, facilidade de navegação, eficiência, flexibilidade, confiabilidade, personalização, segurança/privacidade, capacidade de resposta, segurança/confiança, aparência do site e conhecimento do preço, que serviram como base para a pesquisa apresentada nesse artigo.

\section{Procedimentos Metodológicos}

O presente artigo de caráter descritivo (GIL,2010) apresenta as características de qualidade de serviço de aplicativos móveis para delivery de refeição. $\mathrm{O}$ desenvolvimento da pesquisa pelo método dedutivo (GONÇALVES, 2005), permitiu o apoio ao avaliar e descrever os dados obtidos tendo como início a premissa geral retirada da base teórica, responder por meio de levantamento de premissas particulares o objetivo proposto inicialmente de avaliar a qualidade do serviço prestado pelos aplicativos móveis para delivery utilizando a escala SERVQUAL adaptada.

As formas empregadas para obtenção de dados foram à pesquisa bibliográfica e documental, que serviu de embasamento teórico para elaboração das categorias a serem analisadas (GIL, 2010).

A amostra da pesquisa foi composta por conveniência de respondentes usuários de plataformas sociais que conheciam ou não os aplicativos para pedido de refeição, o levantamento foi realizado através da internet via plataformas sociais como Facebook, Whatsapp e e-mail, por meio de um formulário do Google Forms, a pesquisa ocorreu no período de abril a junho de 2017 e obteve 110 respostas das quais todas consideradas válidas para fins de pesquisa.

$\mathrm{O}$ instrumento para coleta dos dados foi um levantamento composto por 24 afirmativas, que poderiam ser classificadas por uma escala de 7 pontos, considerando a opção 1 discordo totalmente e a opção 7 concordo totalmente, conforme modelo de $\mathrm{Li}$ kert. Este instrumento permitiu a coleta, tabulação e análise com abordagem quantitativa para o entendimento do evento proposto (VIRGILLITO, 2010).

Utilizou-se o software SPSS versão 22. Para análise dos dados escolheu-se a análise fatorial, que se caracteriza por um conjunto de técnicas estatísticas com objetivo de estabelecer correlação entre as variáveis e simplificação do modelo. De acordo com Malhotra 
(2006, p. 548), “a análise fatorial é um nome genérico que denota uma classe de procedimentos utilizados essencialmente para redução e resumo dos dados". A análise fatorial ainda permite identificar dimensões latentes com o objetivo de se explicar as correlações que existem entre um conjunto de variáveis. Um fator é uma dimensão subjacente que tem como objetivo explicar as correlações existentes em um conjunto de variáveis (MALHOTRA, 2006).

\section{RESULTADOS E DISCUSSÃo}

Após a coleta dos dados deu-se início à análise fatorial. O primeiro teste foi a análise do KMO (Kaiser-Meyer-Olkin) para mensurar a adequação da amostra e decidir se é possível a utilização da análise fatorial. O valor encontrado para a amostra foi 0,9 que é considerado excelente para a análise (PESTANA;GAGEIRO, 2014).

O passo seguinte foi verificar qual a variância explicada pelo modelo, cuja extração foi efetuada pelo método das "Componentes Principais" e a rotação pelo método "Varimax" obteve uma solução de 3 constructos, que explica cerca de $70 \%$ da variância total, sendo os demais cerca de $29 \%$ explicados por outros fatores (PESTANA;GAGEIRO, 2014).

A análise seguinte foi à verificação da confiabilidade interna dos constructos por meio do uso do Alpha de Cronbach, cujos valores aceitáveis devem estar acima de 0,6 para cada constructo analisado (HAIR et al, 2009).

Os valores encontrados após essa análise são demonstrados na tabela 1, para facilitar a visualização de como se chegou a matriz final de fatores.

Tabela 1 - Alpha de Cronbach dos Fatores de qualidade no serviço de aplicativos para pedidos de refeições.

\begin{tabular}{l|l|l|l}
\hline \multicolumn{4}{l}{ Estatísticas de confiabilidade } \\
\hline Fator & Alfa de Cronbach & N de itens & \\
\hline 1 &, 943 & 10 & Mantido \\
\hline 2 &, 944 & 7 & Mantido \\
\hline 3 &, 875 & 5 & Mantido \\
\hline
\end{tabular}

Fonte: Elaborado por meio dos dados de pesquisa (2017) 
A matriz final dos fatores extraídos pela análise fatorial com supressão de valores de 0,35 e após a aplicação do Alpha de Cronbach é apresentada na Tabela 2 - Matriz de componente rotativa dos construtos, composta por 3 fatores, os quais foram nomeados tendo como base a revisão teórica quando não foi possível fazer o enquadramento de forma direta.

O primeiro fator foi nomeado "Aumento de canais de distribuição sem perda de segurança" por conter variáveis 11, 12, 7, 1, $3,6,13,14,10$ e 15, relacionados à percepção de serviço de entrega e adaptação às necessidades dos clientes, facilidade de uso, segurança de dados dos clientes, inovação em serviço para pedido de refeição, feedbacke reparo rápido em caso de erro, que atendem as necessidades dos consumidores em relação ao serviço prestado pelos aplicativos. Segundo Las Casas (2012), Kotler e Keller(2012), Oliveira (2007), os serviços devem evidenciar as qualidades percebidas pelos clientes a fim de tornar possível a tangibilidade do serviço prestado, cabendo somente ao prestador de serviço "administrar as evidências" com o propósito de atestar o intangível. As variáveis apontadas neste fator também demonstram a confiabilidade do consumidor ao aplicativo com a segurança de dados pessoais e financeiros no uso.

O segundo fator nomeado, "Interface gráfica do aplicativo", por conter as variáveis 21, 19, 20, 23, 24, 17 e 22, refere-se ao design e aparência e atualizações do aplicativo, inovação e forma moderna de solicitação de refeição, praticidade por prestar um serviço que está disponível $24 \mathrm{~h}$ por dia na percepção do cliente, está relacionado à conveniência das transações online, a facilidade e a diversidade de produtos de acordo com Pi, Liao e Chen (2012), é um fator que chama a atenção dos consumidores por também lhe conferir o empoderamento sobre seus pedidos, uma vez que este consumidor mudou seu relacionamento com o prestador de serviço através da internet.

O terceiro fator nomeado, "Aplicativos como plataforma para resolução de problemas", por conter as variáveis 16, 9, 8, 18 e 5, referindo controle total da compra pelo consumidor, resolução rápida de problemas com o pedido, a rapidez de atendimento em comparação ao atendimento telefônico, relação custo benefício ao utilizar o aplicativo para solicitar a refeição, a capacidade do aplicativo de adaptação ao usuário que relaciona com o fator aumento 
de canais de distribuição sem perda de segurança, opções em serviços de entrega e refeições dentro de uma única ferramenta, e relacionam com o fator aumento de canais de distribuição sem preda de segurança ao evidenciar variáveis que apontam a confiabilidade nos dados dos clientes, ampliação de serviços de entrega e restaurantes, adaptação de variação nos níveis de serviços demandados pelos usuários, reforçando o empoderamento do novo consumidor, ou como destacado por Las Casas (2012), Kotler e Keller (2012), Oliveira (2007) um consumidor em transformação constante e que não aceita um serviço básico de qualidade baixa e duvidosa.

Tabela 2 - Matriz de componente rotativa dos construtos

\begin{tabular}{|c|c|c|c|c|}
\hline & \multirow[t]{2}{*}{ Matriz de componente rotativa ${ }^{a}$} & \multicolumn{3}{|c|}{ Component } \\
\hline & & 1 & 2 & 3 \\
\hline \multirow{3}{*}{ 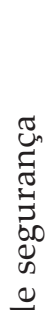 } & $\begin{array}{l}\text { 11) Os aplicativos possuem capacidade de se adaptar em } \\
\text { relação as necessidades dos clientes. }\end{array}$ & .775 & & \\
\hline & $\begin{array}{l}\text { 12) Os aplicativos oferecem uma gama de serviços de entrega } \\
\text { e tipos de restaurantes que justificam a sua utilização. }\end{array}$ & .729 & & \\
\hline & $\begin{array}{l}\text { 7) Os aplicativos lidam de forma bem criteriosa em rela- } \\
\text { ção aos dados dos clientes. }\end{array}$ & .711 & & \\
\hline$\underbrace{\tilde{\sigma}}_{0}$ & $\begin{array}{l}\text { 1) Os aplicativos para pedir comida sempre são fáceis de } \\
\text { utilizar. }\end{array}$ & .709 & & \\
\hline हُ & $\begin{array}{l}\text { 3) Os aplicativos geralmente oferecem bastante informa- } \\
\text { ções sobre os restaurantes e os pratos oferecidos. }\end{array}$ & .694 & & \\
\hline 苂 & 6) Os aplicativos são bastante amigáveis e simples. & .663 & & \\
\hline 葛 & $\begin{array}{l}\text { 13) Os aplicativos de pedido de comida possuem uma grande } \\
\text { habilidade em introduzir novos serviços para os clientes. }\end{array}$ & .660 & & \\
\hline 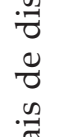 & $\begin{array}{l}\text { 14) Na minha percepção os aplicativos proveem uma ca- } \\
\text { pacidade para os restaurantes de se adaptar as variações } \\
\text { nos níveis de serviços demandados pelos usuários. }\end{array}$ & .652 & & \\
\hline U్త & $\begin{array}{l}\text { 10) Os aplicativos sempre transmitem segurança durante } \\
\text { o processo de prestação de serviços. }\end{array}$ & .640 & & \\
\hline 吕 & $\begin{array}{l}\text { 15) Em minha percepção os aplicativos fornecem ao } \\
\text { restaurante uma habilidade de se recuperar de uma falha } \\
\text { percebida pelo usuário sendo capazes de reparar essa } \\
\text { falha durante o processo. }\end{array}$ & .615 & & \\
\hline
\end{tabular}




\begin{tabular}{|c|c|c|c|}
\hline \multirow{7}{*}{ 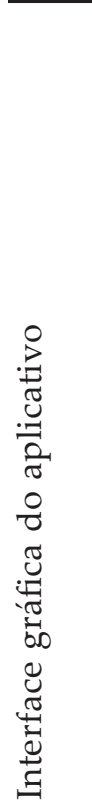 } & 21) Os aplicativos são sempre visualmente atraentes. & .795 & \\
\hline & $\begin{array}{l}\text { 19) A interface dos aplicativos normalmente possui uma } \\
\text { aparência agradável. }\end{array}$ & .774 & \\
\hline & $\begin{array}{l}\text { 20) Os aplicativos são uma forma moderna de prestação } \\
\text { de serviços. }\end{array}$ & .769 & \\
\hline & $\begin{array}{l}\text { 23) Em relação a comunicação os aplicativos sempre pos- } \\
\text { suem um visual atraente. }\end{array}$ & .731 & \\
\hline & $\begin{array}{l}\text { 24) Quanto a aparência os aplicativos sempre possuem } \\
\text { um visual interessante, o que aumenta o meu desejo de } \\
\text { comprar. }\end{array}$ & .668 & \\
\hline & $\begin{array}{l}\text { 17) O fato dos aplicativos informarem o horário de aber- } \\
\text { tura e fechamento dos restaurantes, permite ao usuário } \\
\text { ter um controle maior sobre o seu tempo disponível para } \\
\text { a utilização dos serviços. }\end{array}$ & .632 & \\
\hline & $\begin{array}{l}\text { 22) A taxa de atualizações no visual dos aplicativos faz } \\
\text { com que sempre estejam funcionais. }\end{array}$ & .572 & \\
\hline \multirow{6}{*}{ 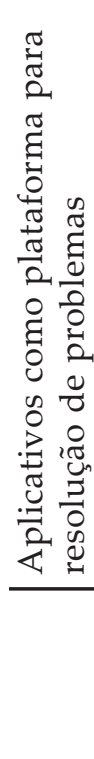 } & $\begin{array}{l}\text { 16) Os aplicativos têm capacidade para traduzir as expec- } \\
\text { tativas dos usuários em ações concretas e rápidas, mini- } \\
\text { mizando a sensação de espera pelo uso do serviço. }\end{array}$ & & .757 \\
\hline & $\begin{array}{l}\text { 9) Os empregados dos restaurantes em geral são bastan- } \\
\text { te atenciosos para resolver os problemas em relação ao } \\
\text { tempo dos pedidos. }\end{array}$ & & .749 \\
\hline & $\begin{array}{l}\text { 8) Quando encontro problemas com os restaurantes os } \\
\text { aplicativos ajudam a solucioná-los. }\end{array}$ & & .680 \\
\hline & $\begin{array}{l}\text { 18) Percebo que é mais rápido ser atendido por aplicati- } \\
\text { vos do que por telefone. }\end{array}$ & & .673 \\
\hline & $\begin{array}{l}\text { 5) O benefício oferecido pelos aplicativos compensa os } \\
\text { custos. }\end{array}$ & & .597 \\
\hline & $\begin{array}{l}\text { Método de Extração: Análise de Componente Principal. } \\
\text { Método de Rotação: Varimax com Normalização de Kai- } \\
\text { ser.a } \\
\text { a. Rotação convergida em } 24 \text { iterações. }\end{array}$ & & \\
\hline
\end{tabular}

Fonte: Elaborado pelos autores por meio dos dados de pesquisa 


\section{CONSIDERAÇõES FINAIS}

A adaptação da escala Servqual para avaliar a qualidade do serviço online prestado por aplicativos móveis para delivery demonstrou aplicabilidade e mensurou os serviços de solicitação de refeição por aplicativos móveis. O método Servqual adaptado proporcionou as informações necessárias para realização desta pesquisa, sendo adequado e gerando resultados compatíveis e confiáveis sem perder o rigor científico.

Através dos resultados da pesquisa os aplicativos móveis para delivery de refeições conseguiram padronizar o processo de execução do serviço para um problema de um grupo de restaurantes como estratégia para tornar um serviço intangível em tangível, trabalhando com um agrupamento maior de restaurantes e oferecer aos clientes(usuários) um menu diversificado e personalizado na comodidade do lar e com o empoderamento total do comando de tempo, espaço e dinâmica de prestação de serviço em entrega delivery de produto por meio de aplicativos móveis.

O objetivo do trabalho foi atingido ao se aplicar a análise fatorial aos dados obtidos por meio da pesquisa e extrair os três fatores que compuseram a avaliação da qualidade do serviço online prestado por aplicativos móveis para delivery.

O fator 1, aumento do canal de distribuição sem a perda de segurança, demonstrou que o consumidor percebe a qualidade do serviço de entrega e confia que suas informações estão seguras com os prestadores do serviço, a segurança é foco e preocupação da tecnologia da informação na prestação de serviços on line e fica evidente que se transformou em um valor tangível para caracterização de serviços de qualidade.

O fator 2, interface gráfica do aplicativo referente à percepção do usuário e ao design do aplicativo, demonstra que as empresas estão investindo na manutenção dos seus serviços conforme esse novo consumidor em constante transformação que é exigente ao solicitar um serviço, a percepção da qualidade do design pelo consumidor (usuário) emerge como um fator determinante para o desenvolvimento de outros aplicativos moveis para delivery.

O fator 3, finalmente aponta que os aplicativos de delivery também entregam com qualidade o empoderamento do consumidor 
no controle total do seu pedido, ficando evidente com as variáveis apontadas pela análise fatorial indicando que os aplicativos tem a capacidade de traduzir as expectativas destes usuários em ações concretas e rápidas para realizar o pedido sem intermediários e reduzindo as possibilidades de erros uma vez que este cliente/ usuário é que tem o domínio da interface apresentada, a relação custo benefício uma vez que este cliente/usuário não perdeu seu tempo em filas de espera ou telefones ocupados e atendentes sem treinamento adequado para atendimento e uma variabilidade no tipo de serviços de entrega e restaurantes, a adaptação e o serviço personalizado tão importante para que este cliente/usuário sinta-se importante e único no momento de usufruir do serviço.

Futuros pesquisadores podem explorar mais o tema para que dados e resultados forneçam informações sobre a qualidade dos aplicativos móveis de pedidos de refeição e agregar modelos de atendimento ao cliente/usuário utilizando os dados de feedback que os clientes (usuários) deixam no próprio aplicativo.

\section{REFERÊNCIAS}

ABIA. ABIA debateu sobre tendências e inovação no $8^{\circ}$ Congresso Internacional de Food Service. Disponível em: <http://abia.org.br/vsN/tmp_2.aspx?id=49> Acesso em 20 Jun-2016.

ABRASEL. Alimentação fora do lar movimenta bilhões de reais. 2017(a) Disponível em < http://www.abrasel.com.br/component/content/article/7-noticias/5465-17082017-alimentacao-fora-do-lar-gera-bilhoes-de-reais.html> Acesso em 11 fev. 2017.

ABRASEL. Aplicativos de refeição entram na corrida da entrega rápida. 2017 (b).Disponível em <http://www.abrasel.com.br/component/content/article/7-noticias/4986-23012017-aplicativos-de-refeicao-entram-na-corrida-da-entrega-rapida.html> Acesso em 07 Jul. 2017.

BALASUBRAMANIAN, S.; PETERSON, R. A.; JARVENPAA, S. L. Exploring the implications of $\mathrm{m}$-commerce for markets and marketing. Journal of the academy of Marketing Science, 30(4), 348. 2002.

BHAT, M. A. Tourism service quality: A dimension-specific assessment of SERVQUAL. Global Business Review, v. 13, n. 2, p. 327-337, 2012.

CHURCHILL JR, G.; PETER, P. J. Marketing - Criando valor para os clientes. São Paulo: Saraiva, 2000.

CIRILO, C. E. Computação Ubíqua: definição, princípios e tecnologias. 2007. Disponível em:<https://www.academia.edu/1733697/Computacao_Ubiqua_definicao_principios_e_tecnologias>. Acesso em: $07 \mathrm{j}=\mathrm{jul} .2017$.

COBRA, M. Administração de Marketing. São Paulo: Atlas, 1992. 
EXAME. Como os aplicativos de delivery vêm mudando o mercado de entrega de comida no Brasil. Disponível em <https://exame.abril.com.br/negocios/dino/como-os-aplicativos-de-delivery-vem-mudando-o-mercado-de-entrega-de-comida-no-brasil/> Acesso em 22 ago.2017

EXAME. Com apetite de unicórnio, iFood quer se reinventar. Disponível em $<\mathrm{https}: /$ exame. abril.com.br/revista-exame/com-apetite-de-unicornio/> Acesso em 22 fev.2018.

GIL, A. C. Como elaborar projetos de pesquisa. 5. ed. São Paulo: Atlas, 2010.

GONÇALVES, H. Manual de metodologia da pesquisa científica. São Paulo: Avercamp, 2005.

GRÖNROOS, C. Relationship marketing readiness: theoretical background and measurement directions. Journal of Services Marketing, Vol. 31 Issue: 3, pp.218-225,2017. DOI: https://doi. org/10.1108/JSM-02-2017-0056>

HAIR, J. F. et al. Análise multivariada de dados. 6. ed. Porto Alegre: Bookman Editora, 2009.

HOFFMAN, D. K; BATESON, J. E. G.; IKEDA, A. A.; CAMPOMAR, M. C. Princípios de Marketing de Serviços. São Paulo: Cengage Learning, 2009.

IDC. Mercado brasileiro de celulares desacelera no terceiro trimestre de 2017, revela IDC Brasil. Disponível em <http://www.idcbrasil.com.br/releases/news.aspx?id=2258> Acesso em 11 fev.2018.

IFB - INSTITUTO FOOD SERVICE BRASIL. 2017. Disponível em < http://www.institutofoodservicebrasil.org.br/> Acesso em 22 fev.2018.

ISTO É DINHEIRO. iFood cria portal para vender produtos a restaurantes. 2017. Disponível em < https://www.istoedinheiro.com.br/ifood-cria-portal-para-vender-produtos-restaurantes/> Acesso em 22 fev.2018.

JORNAL O ESTADO DE SÃO PAULO. Até o fim de 2017, Brasil terá um smartphone por habitante, diz FGV. O Estado de São Paulo, 19 abr. 2004. Disponível em < http://link.estadao.com.br/noticias/gadget, ate-o-fim-de-2017-brasil-tera-um-smartphone-por-habitante-diz-pesquisa-da-fgv,70001744407> Acesso em 11 fev.2018.

KOTLER, P.; KELLER, K. L. Administração de Marketing. 14ª Ed. São Paulo: Pearson Prentice Hall, 2012.

LAS CASAS, A. L. Marketing de Serviços. São Paulo: Atlas, 2012.

LOVELOCK, C.; W., L. Serviços: Marketing e gestão. São Paulo: Saraiva, 2003.

MALHOTRA, N. Pesquisa de marketing: uma orientação aplicada. 4.ed. porto alegre: bookman, 2006.

MATEUS, G. R.; LOUREIRO, A. A. F. Introdução à computação móvel. 1998.Disponível em:<http://homepages.dcc.ufmg.br/ loureiro/cm/docs/cm_livro_1e.pdf >. Acesso em 07 jul. 2017.

Meio \& mensagem. Pesquisa do ifood revela hábitos de consumo no delivery. 2016. Disponível em <http://www.meioemensagem.com.br/home/marketing/2016/07/01/pesquisa-do-ifood-revela-habitos-de-consumo-no-delivery.html> acesso em 01 jun.2016.

MORAES, T. A. Qualidade em Serviços e Dispositivos Móveis: Uma Análise a Partir da Aplicação do Modelo Servqual/Quality in Services and Mobile Devices: Na Analysis From Application of Servqual Model. Revista FSA (Faculdade Santo Agostinho), v. 14, n. 4, p. 19-39, 2017. 
MORT, G. S.; DRENNAN, J. Marketing m-services: Establishing a usage benefit typology related to mobile user characteristics. Journal of Data base Marketing \& Customer Strategy Management, 12(4), 327-341. 2005.

OLIVEIRA, S. L. I. Desmistificando o Marketing. São Paulo: Novatec Editora, 2007.

ÖZTAŞ, Y. B. B. The increasing importance of mobile marketing in the light of the improvement of mobile phones, confronted problems on countered in practice, solution of fersand expectations. Procedia-Social and Behavioral Sciences, 195, 1066-1073. 2015.

PESTANA, M. H.; GAGEIRO, J. N. Análise de dados para ciências sociais: a complementaridade do SPSS. 6. ed. Lisboa: Edições Sílabo, 2014.

PI, S.; LIAO, H.; CHEN,H. Factors That Affect Consumers' Trust and Continuous Adoption of Online Financial Services. International Journal of Business and Management, 9, Vol. 7n. 9. Maio 2012, pp.108-119.

ROCHA, A.; FERREIRA DA SILVA, J. Marketing de serviços: retrospectiva e tendências. Revista de administração de empresas, v. 46, n. 4, p. 1-9, 2006.

ROCHA, M. (org.); READE, D.; MOLA, J..; OLIVEIRA, S. L. I. Marketing Estratégico. São Paulo: Saraiva, 2015.

SANEMATSU, L.; SILVA, A.; VIEIRA, A. Relação entre Fabricante e Varejista: um Estudo Qualitativo Comparativo no Setor de Peças Automotivas. NAVUS - Revista de Gestão e Tecnologia, v. 6, n. 3, p. 56-69, 2016.

SEBRAE. Nota conjuntural - Setor de alimentos. 2016. Disponível em: $<$ https://www.sebrae. com.br/Sebrae/Portal\%20Sebrae/UFs/RJ/Menu\%20Institucional/Sebrae_SET_dez12_alim.pdf> Acesso em 29 nov.2016.

SILVA, J. F.; ROCHA, A. Marketing de serviços: retrospectivas e tendências. REA. Out/dez 2006. P.79-87.

VARGO, S. L.; LUSCH, R. L. Envolving to a New Dominant Logic for Marketing. Journal of Marketing, 68, 2004.

VARGO, S. L.; LUSCH, R. F. Why "service"? Journal of the Academy of marketing Science, v. 36, n. 1, p. 25-38, 2008.

VIRGILliTO, S. B. Pesquisa de Marketing: uma abordagem quantitativa e qualitativa. São Paulo: Saraiva. 2010. 500p

ZEITHAML, V. A.; PARASURAMAN, A.; MALHOTRA, A. A conceptual framework for understanding e-service quality: implications for future research and managerial practice. Marketing Science Institute Working Paper. Report No. 00-115, 2000.

Recebido em: 26-2-2018

Aprovado em: 5-6-2019

Avaliado pelo sistema double blind review.

Disponível em http://mjs.metodista.br/index.php/roc 